DOI: 10.5212/Publ.Biologicas.v.20i2.0006

\title{
CEREUS JAMACARU DE CANDOLLE (CACTACEAE), O MANDACARU DO NORDESTE BRASILEIRO
}

\section{CEREUS JAMACARU DE CANDOLLE (CACTACEAE), MANDACARU THE NORTHEASTERN BRAZIL}

\author{
Michele de Sousa LEAL SALES ${ }^{1}$, Lívia do Vale MARTINS ${ }^{2}$, Iael de SOUZA ${ }^{3}$, Maria do \\ Socorro MEIRELES DE DEUS ${ }^{4}$, Ana Paula PERON ${ }^{5,+,}$ \\ ${ }^{1}$ Acadêmica do Curso de Ciências Biológicas. Campus Senador Helvídio Nunes de Barros. \\ Universidade Federal do Piauí. \\ ${ }^{2}$ Acadêmica do Curso de Pós-Graduação em Genética e Melhoramento. Campus Ministro \\ Petrônio Portella. Universidade Federal do Piauí. \\ ${ }^{3}$ Socióloga. Mestre em Sociologia. Docente do Curso de História. Campus Senador Helvídio \\ Nunes de Barros. Universidade Federal do Piauí. \\ ${ }^{4}$ Bióloga. Doutoranda em Ecologia. Docente do Curso do Ciências Biológicas. Campus \\ Senador Helvídio Nunes de Barros. Universidade Federal do Piauí. \\ ${ }^{5}$ Bióloga. Doutora em Genética e Melhoramento. Docente do Curso de Ciências Biológi- \\ cas. Campus Senador Helvídio Nunes de Barro. Universidade Federal do Piauí. Docente e \\ Orientadora do Curso de Pós-Graduação em Genética e Melhoramento. Campus Ministro \\ Petrônio Portella. Universidade Federal do Piauí. \\ Endereço Profissional dos Autores: Rua Cícero Duarte, 940. Bairro Junco. Universidade \\ Federal do Piauí (UFPI). Campus Senador Helvídio Nunes de Barros (CSHNB). Núcleo de \\ Pesquisa Aplicada à Saúde e ao Meio-Ambiente (NUPBSAM). Laboratório de Citogenética \\ Vegetal e Animal. Picos, Piauí. CEP 64600-000. \\ +Bairro Iningá. Universidade Federal do Piauí (UFPI). Campus Ministro Petrônio Portela \\ (CMPP). Centro de Ciências Agrárias (CCA). Teresina, Piauí. CEP 64049-550 \\ *Autor para correspondência: Ana Paula Peron, e-mail: anapaulaperon@ufpi.edu.br
}

Data de recebimento: 10/03/2014

Data da aprovação: 30/06/2014

\section{RESUMO}

Este estudo teve por objetivo reunir informações, por meio de uma revisão da literatura científica, sobre a importância medicinal, econômica e ambiental da espécie C. jamacaru, o popular mandacaru, para a Região Nordeste do Brasil, com o intuito de estimular, cada vez mais, pesquisadores das mais diversas áreas em estudá-la e explorá-la cientificamente em benefício da população que dela depende. Esta planta predomina na caatinga devido à sua grande adaptação fisiológica, sobrevivendo a secas prolongadas. As camadas populares utilizam-na para a amenização de diversos males, como problemas nos rins e nos sistemas circulatório e digestório. Estudos científicos também demonstraram outros benefícios, como ação vasodilatadora e a propriedade de modificar o acúmulo e a liberação de norepinefrina nas terminações nervosas em algumas espécies de roedores. Também é utilizada como fonte de alimento e água, e por causa do seu porte arbóreo é de grande serventia na construção de casas. Também possui expressiva importância ambiental servindo de alimento para insetos. Estes aspectos são suficientes e relevantes para que os órgãos de fomento à pesquisa apoiem as iniciativas dos pesquisadores, salvaguardando o modo de vida das comunidades carentes, como também possibilitando a fabricação de novos fármacos, que poderão servir de matériaprima de exportação para outras regiões do Brasil.

Palavras-chave: Cactoideae. Cultura popular. Pesquisa científica. Atividades econômicas. 


\begin{abstract}
This study aimed to gather information through a review of scientific literature on medical, economic and enviromental importance of the species $C$. jamacaru, the popular mandacaru for the northeast region of Brazil with the aim of stimulating increasingly researchers from various fields in studying it and explore it scientifically for the benefit of the population that depends on it. This plant predominates in the bush because its large physiological adaptation, surviving prolonged droughts. The working classes use it for alleviation of various aliments, incluinding kidney problems and circulatory and digestive systems. Scientific studies have also shown other benefits such as vasodilation and property to modify the accumulation and release of norepinephrine at the nerve endings in some rodent species. These aspects are relevant and sufficient for organs for research funding support initiatives from researchers, while safeguarding the livelihoods of poor communities, as well as enabling the manufacturing of new drugs, which could serve as raw material for export to other regions Brazil.
\end{abstract}

Keywords: Cactoideae. Popular culture. Scientific research. Economic activities.

\section{Introdução}

A família Cactaceae (Juss.) possui mais de 125 gêneros e 2.000 espécies presentes em todo o mundo. O Brasil é considerado o terceiro maior centro de diversidade desta família, com 35 gêneros e 237 espécies distribuídas em todo o seu território. (ORTEGA-BAES; GODÍNEZ-ÁLVAREZ, 2006). Neste país a maior variedade de Cactaceae encontra-se na Região Nordeste, no bioma Caatinga, com cerca de 24 gêneros, com destaque aos gêneros Cereus, Opuntia e Pilosocereus, e 88 espécies, sendo estas plantas muito importantes para a conservação da biodiversidade local. (REGO et al. 2009). O gênero Cereus caracteriza-se por apresentar caule (cladódio) verde, alongado com gomos longitudinais, flores isoladas grandes e de colorido vistoso. Os frutos são basiformes e, em geral, grandes e vermelhos, de polpa adocicada, e muito apreciados por animais e pelo homem. (ANDERSON, 2001; LANDGRAF; PAIVA, 2009).

Nesta região, uma das espécies de maior importância medicinal, econômica e ambiental é a C. jamacaru De Candole, popularmente conhecida como mandacaru, sendo encontrada em áreas urbanas, litorais e pastos. (ROCHA; AGRA, 2002). Esta planta é amplamente utilizada pela população desta região na construção civil, na cura ou amenização de doenças, como forrageira e em ornamentação. No entanto, de acordo com Rego et al. (2009), o conhecimento da população brasileira sobre sua utilização e benefícios bem como o conhecimento de pesquisadores sobre as potencialidades desta cactácea ainda são incipientes.

Dessa forma, levando-se em conta a importância do C. jamacaru para o Nordeste brasileiro, considerando que relatos a seu respeito encontram-se dispersos na literatura e que, até o momento, ainda não foi realizada uma sistematização sobre eles, este trabalho teve por objetivo reunir informações, por meio de uma revisão na literatura científica, sobre a importância medicinal, econômica e ambiental da espécie C. jamacaru, demonstrando razões para que órgãos de fomento subsidiem pesquisas envolvendo esta cactácea.

\section{Metodologia}

Para uma completa revisão, somente fontes primárias foram usadas. As bases de dados pesquisadas foram MEDLINE (Medical Literature Analysis and Retrieval System Online), SciELO (Scientific Eletronic Library Online) e PubMed. As informações disponibilizadas em inglês ou português foram coletadas usando as seguintes palavras-chave: Cactaceae, Cereus spp, Cereus jamacaru De Candolle, aspectos botânicos, importância medicinal, importância econômica, importância ambiental.

\section{Desenvolvimento}

- Aspectos gerais sobre a Família Cactaceae e o Gênero Cereus

A família Cactaceae, pertencente à Divisão Angiospermae (Joly), é considerada um grupo 
altamente especializado, com plantas variando de ervas e arbustos a árvores de até 10 metros de altura. No entanto, é possível encontrar espécies epífitas e escandentes em ambientes úmidos, como no litoral. As plantas desta família são endêmicas nos continentes americanos, com exceção da espécie Rhipsalis baccifera, e ocorrem desde as Américas até o Srilanka (RAMALHO et al., 2009). Estas cactáceas, em sua grande maioria, caracterizam-se pela variação morfológica de seus caules, que normalmente apresentam ramos vegetativos normais reduzidos (aréolas) capazes de produzir folhas, espinhos e/ou flores (MEIADO et al., 2010).

A classificação atual, proposta por Wallace (1995), distribui os representantes das cactáceas em três subfamílias, Opuntioideae, Pereskiodeae e Cactoideae. A Cactoideae é a mais numerosa em gêneros e em número de espécies, e a mais diversificada em termos de formas e hábitos, sendo subdividida em nove tribos. Entre estas tribos está a Cereeae, que se destaca como a mais representativa no Brasil, com 12 gêneros identificados e amplamente encontrada na Região Nordeste, que é considerada o terceiro maior centro de diversidade para as Cactaceae no mundo (DAVET, 2005).

Dentre os gêneros pertencentes à tribo Cereeae, encontra-se o gênero Cereus, cujas espécies estão presentes desde a Índia até a América do Sul. Este gênero é bastante expressivo na constituição da flora de vários estados brasileiros, onde se encontram distribuídas cerca de 40 espécies (TAYLOR; ZAPPI, 2004). No geral, os seus representantes compreendem plantas de porte arbustivo ou arbóreo, que não apresentam folhas, de caules suculento e eretos do tipo colunar, com número e disposição de costelas longitudinais variáveis, nas quais estão inseridos botões axilares contendo espinhos (DAVET et al., 2009).

$\mathrm{O}$ gênero Cereus foi primeiramente descrito por Hermann, em 1628, e depois por Miller, em 1754. De acordo com Davet (2005), as suas espécies mais conhecidas e utilizadas pela população são: Cereus adeemani, Cereus bicolor, Cereus comarapanus, Cereus friccie, Cereus jamacaru, Cereus hildmannianus, Cereus repandus, Cereus trigonodendron e Cereus vargasianus. Segundo este mesmo autor, uma das espécies de Cereus mais encontradas e de grande importância medicinal, econômica e ambien- tal para o Nordeste brasileiro é o Cereus jamacaru De Candolle.

- Aspectos botânicos do C. jamacaru, o mandacaru do Nordeste brasileiro

O cacto C. jamacaru, espécie nativa da vegetação da caatinga brasileira, cresce em solos pobres em nutrientes e pedregosos, e juntamente com outras espécies de cactáceas formam a paisagem típica da região semiárida do Nordeste do Brasil. É amplamente encontrado nos estados do Piauí, Ceará, Rio Grande do Norte, Paraíba, Pernambuco, Alagoas, Sergipe, Bahia e norte de Minas Gerais (TAYLOR; ZAPPI, 2004).

As plantas desta espécie podem chegar a 10 metros de altura, dependendo do ambiente. Possuem tronco lenhoso com muitos ramos eretos, dando ao topo do cacto um aspecto compacto. Os ramos novos são azulados e possuem de 4 a 6 costelas de ápices obtusos, separados por sulcos profundos. As aréolas são circulares, distantes de $2 \mathrm{~cm}$ a $5 \mathrm{~cm}$ entre si, sendo maiores no tronco principal. Os espinhos, de coloração amarela, vermelha ou marrom, são radiais, medindo de $9 \mathrm{~cm}$ a $30 \mathrm{~cm}$ de comprimento (DAVET, 2005).

Suas flores são solitárias, noturnas, laterais e subapicais, brancas, de $20 \mathrm{~cm}$ a $30 \mathrm{~cm}$ de comprimento, $1,5 \mathrm{~cm}$ de diâmetro, recobertas de escamas largas e oblongas de cor verde-escura. Os frutos, nos quais se encontram inúmeras sementes de cor preta e bem pequenas, são elipsoides, de $05 \mathrm{~cm}$ a $12 \mathrm{~cm}$ de diâmetro, alaranjados ou vermelhos, com polpa mucilaginosa branca, de aroma suave, comestível e doce (MEIADO et al., 2010).

Esta cactácea apresenta adaptações morfológicas e fisiológicas marcantes, como a presença de caule fotossinteticamente ativo e sistemas radiculares superficiais e extensos, que proporcionam rápida absorção de água depois de uma seca prolongada. Possui cera epicuticular, cutícula espessa, estômatos localizados em depressões da epiderme e hipoderme colenquimática, que também servem para amenizar a perda de água para o ambiente (TAYLOR; ZAPPI, 2008).

Em razão de colonizarem ambientes com altas temperaturas e com baixa umidade relativa do ar, estas plantas, assim como outras cactáceas, possuem adaptação fisiológica chamada de metabolismo ácido das crassuláceas (CAM), que lhes proporciona maior 
eficiência no uso da água, permitindo assim que sobrevivam em ambientes com elevado défice hídrico, sem que haja grande comprometimento em sua taxa fotossintética (HERNÁNDEZ-GONZÁLEZ; VILLARREAL, 2007). Elas apresentam, ainda, alta relação volume/superfície, com células parenquimáticas especializadas em armazenar água e o desenvolvimento de grandes proporções de tecido parenquimático com células constituídas por mucilagem, adaptações estas que também proporcionam grande resistência a secas prolongadas (DETTKE; MILANEZE-GUTIERRE, 2008).

$\mathrm{Na}$ constituição fitoquímica do caule e raízes do mandacaru encontram-se nitrato de sódio, B-sisterol, as aminas tiramina, N-metilamida e horderina, e muitas fibras. No caules e nas folhas há predomínio de ácidos graxos insaturados, como o oleico e o linoleico; entre os saturados predominam os ácidos palmítico, cítrico, ascórbico, esteárico, betalaína e indicaxantina (MEIADO et al., 2010). Já nas sementes há predomínio de ácidos graxos insaturados, destacando-se o oleico e o linoleico, e entre os saturados predominam o palmítico e o esteárico, e a presença de muitas fibras (DAVET, 2009).

O mandacaru possui grande importância medicinal, sendo muito utilizado na medicina tradicional do Nordeste brasileiro, principalmente pela população mais carente, sendo, na maior parte das vezes, um dos únicos recursos terapêuticos acessíveis a essas pessoas.

\section{- Importância medicinal do C. jamacaru}

Há décadas a população carente do Nordeste utiliza as raízes do mandacaru, em infusão (chá), como diuréticas e no tratamento de outros problemas renais, sendo que, durante o tratamento, trocam a ingestão de água por este chá até o desaparecimento dos sintomas. A mesma população também utiliza a infusão do caule desta cactácea para obter ação emenagoga, anticonstipante, anti-hipertensiva, antirreumática e antiemética (PAULINO et al., 2011).

De acordo com Guedes et al. (2009), a cultura popular igualmente utiliza o caule de mandacaru, em infusão, no controle da albuminúria, diabetes, no tratamento de problemas vesiculares e na amenização de problemas respiratórios, como tosse e bronquite. Citam ainda que a polpa do fruto desta cactácea in natura é muito utilizada para o tratamento de úlceras e no combate ao escorbuto. Gonzáles-Hernández e
Villarreal (2007) relatam que a população nordestina carente faz uso das flores de C. jamacaru, em infusão ou in natura, para o tratamento de verminoses, de furúnculos, abcessos e na amenização de febres.

Andrade et al. (2006), pesquisando dois grupos indígenas, os xocós, em Sergipe, e os kariris-xocó, em Alagoas, verificaram que estas comunidades preparam um chá a partir da mistura das raízes de mandacaru com as folhas de Senna uniflora L. e de Senna obtusifolia L. para curar problemas intestinais e respiratórios, e para amenização de febres. Relatam também que esses dois grupos indígenas fazem o uso tópico do macerado do caule in natura deste cacto para o tratamento de hemorroidas.

Alguns trabalhos científicos sobre a ação medicinal desta planta foram encontrados na literatura, dentre eles está o realizado por Messias et al. (2010), que verificaram que o caule de mandacaru possui atividades antimicrobiana e vasodilatadora em roedores. Andrade et al. (2006), em avaliações laboratoriais realizadas com mamíferos, mencionam que o caule in natura deste cacto demonstrou ter propriedades anti-inflamatória e anticonceptiva. Relatam ainda que a ação da tiramina encontrada no caule e raízes tem ação cicatrizante e antifúngica em pele de roedores.

Em outra pesquisa, Oliveira e Machado (2003) relataram que o extrato hidroalcoólico do caule de $\mathbf{C}$. jamacaru tem propriedade de inibir o crescimento tumoral em camundongos com sarcoma linhagem 180, um tipo de câncer peritoneal. Em um estudo realizado por Bruton et al. (2006), tendo como organismo-teste camundongos, foi verificado que a tiramina presente no cladódio de mandacaru age modificando o acúmulo e a liberação do neurotransmissor norepinefrina nas terminações nervosas, demonstrando assim potencial para a amenização do mal de Parkinson e ação cardiotônica (atividade simpatomimética). Já Vatta et al. (2011), em um estudo com carneiros, verificaram que a ingestão do caule in natura de $\mathbf{C}$. jamacaru possui ação anti-helmíntica.

Considerando que existem poucos estudos laboratoriais que confirmem os relatos feitos pela cultura popular em relação à ação medicinal do $\mathbf{C}$. jamacaru, faz-se necessário um estudo aprofundado sobre as reais propriedades medicinais desta cactácea. Davet et al. (2009) sugerem que os pesquisadores olhem com mais atenção para o mandacaru, valorizando sua constituição fitoquímica. Ressaltam ainda 
que os medicamentos naturais com comprovada atividade farmacológica, comercializados pelas indústrias farmacêuticas, são economicamente mais acessíveis à população, não somente do Nordeste, mas de todo o Brasil.

Além de importância medicinal, o mandacaru também possui importante função econômica e ambiental para a Região Nordeste do Brasil, sendo, muitas vezes, um dos poucos recursos de renda para muitas famílias, e recurso alimentar para animais e, muitas vezes, para o próprio homem, durante o período de seca prolongada.

- Importância econômica e ambiental do C. jamacaru

No Nordeste brasileiro, o fenômeno da seca causa sérios prejuízos ao setor agropecuário. Por isto, a região necessita de manejo sustentável, com sistemas agrícolas fundamentados no uso de cultivos adaptados às suas condições. O C. jamacaru é muito importante para esta região do país, principalmente durante a seca prolongada, que ocorre no segundo semestre do ano, servindo como recurso forrageiro estratégico na composição das dietas dos ruminantes e atendendo parte do requerimento de água destes animais. (CAVALCANTI; RESENDE, 2006; MEIADO et al., 2010).

Em razão disto, muitos agropecuaristas do sertão nordestino cultivam o mandacaru para sustentar o seu rebanho e para vender a outros pecuaristas. Este cacto, durante o período de grande seca, serve também para alimentar famílias carentes, que consomem o cladódio cozido ou in natura, assim como os seus frutos e suas flores in natura. (DAVET et al., 2009). Muitas famílias preparam compotas de doce da polpa desta cactácea e vendem em beira de estradas e feiras (PAULINO et al., 2011).

O C. jamacaru apresenta um cladódio lenhoso bastante espesso, que pode chegar a $60 \mathrm{~cm}$ de diâmetro. Por causa desta característica, o caule é utilizado pela população de baixa renda como alicerce de casas e na construção de telhados, carroças, reservatórios de água, portas e janelas. Ainda no setor de construção, Lorenzi e Matos (2002) informam que, em teste em laboratório, verificou-se que a mucilagem do caule do mandacaru, quando adicionada em pastas e argamassas de gesso, cal ou cimento, melhora a resistência desses materiais em razão de suas propriedades aditivas, como a impermeabilidade e o aumento da resistência mecânica. Lucena et al. (2012) observam que esta cactácea também é muito utilizada na decorações de interiores, jardins e em projetos paisagístico

Por ter caule suculento e por sua constituição fitoquímica, o cladódio desta planta é importante para indústrias do Nordeste por produzirem ésteres de cera com potencial de aplicação como barreira impermeável e uma goma viscosa, com diversas aplicações industriais (JAYME et al., 2013). Segundo Piletti (2011), testes laboratoriais demonstraram que o cladódio de $\mathbf{C}$. jamacaru pode ser eficiente no tratamento de efluentes, oferecendo menor custo em comparação aos polímeros sintéticos, tendo a vantagem de ser biodegradável,

$\mathrm{O}$ fruto do mandacaru mostra grande potencial para aproveitamento industrial, por apresentar teores elevados de sólidos totais e açúcares totais, constituintes importantes em processos biotecnológicos, como, por exemplo, em fermentação alcoólica (Almeida et al., 2011). Esta fermentação proveniente do suco do fruto de mandacaru produz álcool etílico como produto principal, e muitos outros componentes secundários, como aldeídos, metanol, alcoóis superiores, ácidos e ésteres, que contribuem para a qualidade organoléptica na produção de vinhos e cachaças (DATO et al., 2005). Ainda nesta região, o fruto e o cladódio também são matéria-prima para a produção de cosméticos, como xampus, condicionadores, sabões, cremes, loções, máscaras e géis (VILLASEÑOR, 2008).

Segundo Davet (2009), a composição obtida a partir das sementes de mandacaru assemelha-se à encontrada no óleo de soja, razão pela qual este autor sugere potencial uso em comum entre as duas plantas, ou a substituição do óleo de soja pelo óleo de sementes de $\mathbf{C}$. jamacaru, visto que a extração de óleo das sementes é um processo mais acessível economicamente do que a extração de óleo da leguminosa.

Além da importância econômica, o mandacaru também possui importância ambiental. Santos et al. (2007) referem que o caule desta cactácea é substrato preferido por espécies de vespas sociais para a nidificação e a construção de ninhos. Tais insetos também se alimentam da polpa do fruto desta planta. De acordo com Meiado et al. (2010), as flores do C. jamacaru também são visitadas por espécies de abelhas melíferas, que utilizam seu pólen como alimento, contribuindo assim com a flora apícola da caatinga. O fruto é utilizado como alimento por espécies de morcegos frugíveros, que acabam 
facilitando os processos de polinização e de dispersão das sementes do mandacaru. Estas interações conferem à planta um relevante papel ecológico, pois, além das interações com determinadas espécies de animais, ela também favorece o estabelecimento (facilitação) de determinadas espécimes de plantas menos tolerantes aos fatores edáficos.

Estes dados reforçam a tese de que o mandacaru é essencial à vida da população da Região Nordeste do Brasil e à conservação da biodiversidade do bioma Caatinga. Por tais razões, é necessário um olhar mais atento dos pesquisadores para a região, a fim de que a população local tenha conhecimento da importância da conservação e manutenção desta biodiversidade.

\section{Considerações finais}

É possível observar que os estudos e experimentos aqui mencionados, ainda que sejam incipientes e padeçam com a falta de verbas para financiar, intensificar e avançar nas pesquisas, procuram valorizar e explorar a potencialidade da biodiversidade do Nordeste brasileiro, demonstrando que é possível beneficiar grande parte da população mais carente desse território, comprovando, cientificamente, aquilo que já é posto em prática pela cultura popular, cuja precariedade das condições de vida e trabalho desse grande segmento social o obriga a fazer experimentos para garantir a manutenção da própria vida, uma vez que não dispõe de dinheiro para comprar os produtos farmacológicos, muito menos para se deslocar e chegar aos locais onde são vendidos.

A cultura popular, que é a da sobrevivência e adaptação às adversidades impostas, enquanto efeitos colaterais do processo do desenvolvimento desigual e combinado do capital, apropria-se do mundo reinventando-o, relendo-o, recriando-o no limite das possibilidades postas pelas impossibilidades amargadas. Os animais da caatinga são exemplo a ser imitado. Se eles sobrevivem do mandacaru, os homens também podem fazê-lo. A seca não é tanto um problema geológico e climático, mas sim político e econômico, como já foi demonstrado por Oliveira (1987). E seu enfrentamento requer organização e mobilização permanentes, culminando com uma luta política e ideológica acirrada entre a perspectiva do trabalho e a do capital. Entretanto, o cenário e conjuntura histórico-sociais atuais não são nada promissores. Portanto, cabe aos pesquisadores ao menos tentar reunir esfor- ços para melhorar as condições de vida e trabalho daqueles que sofrem justamente por não tê-las.

Além de o mandacaru garantir a sobrevivência dos animais e dos seres humanos que vivem na região da caatinga, também pode ser utilizado para comercialização, devido às suas características e aos seus derivados potenciais, o que garantiria trabalho e renda para essa população, melhorando sua subsistência e sobrevivência, permitindo que continuasse a viver no local onde nasceu e cresceu e conhece tão bem, evitando as migrações desventurosas para as grandes cidades, já inchadas, saturadas, com sérios problemas estruturais de infraestrutura, jamais resolvidos, porém aprofundados e intensificados. Talvez as estórias narradas por Luiz Gonzaga, na canção $A$ triste partida, pelo filme $O$ homem que virou suco, de João Batista de Andrade, ou as de outros tantos Severinos, como em Morte e vida severina, de João Cabral de Mello Neto, não se repetissem nem se reproduzissem numa espiral sem-fim.

Sendo assim, os órgãos de fomento à pesquisa, fazendo jus ao seu propósito fundante de contribuir para o desenvolvimento da humanidade e melhoria permanente das condições e qualidade de vida e trabalho de todos os seres humanos, sem distinção de cor, classe e status, deveriam ser os primeiros a apoiar e incentivar os pesquisadores para explorar as potencialidades presentes na caatinga nordestina, demonstrando que a ciência é o conhecimento que está a serviço não de uma minoria, nem de uma parcela, nem de centenas, nem de milhares ou milhões, mas, como deve ser, de toda a humanidade.

\section{Referências}

ALMEIDA, M. M.; CONRADO, F. L. H.; CONRADO, L. D. S.; MOTA, J. C.; FREIRE, R.M.M. Estudo cinético e caracterização da bebida fermentada do Cereus jamacaru D.C. Revista Verde de Agroecologia e Desenvolvimento Sustentável, v. 6, n. 2, p. 10-12, 2011.

ANDERSON, E. F. (2001) The cactus family. Portland: Timber Press, Portland, 2001.

ANDRADE, C. T.S.; MARQUES, J. G. W., ZAPPI, D. C. Utilização medicinal de cactáceas por sertanejos baianos. Revista Brasileira de Plantas Medicinais, Campinas, 8, n. 3, p. 36-42, 2006.

BRUTON, L. L.; LAZO, J. S.; PARKER, K. L. As bases farmacológicas da terapêutica. São Paulo: McGraw-HillInteramericana do Brasil, 2006. 
CAVAlCANTI, N. B.; RESENDE, G. M. Consumo do mandacaru (Cereus jamacaru D.C.) por caprinos na época da seca no semiárido de Pernambuco. Revista Caatinga, v. 19, n. 4, p. 402-408, 2006.

DATO, M. C. F.; PIZAURO-JÚNIOR, J. M.; MUTTON, M. J. R. Analysis of the secondary compounds produced by Saccharomyces and wild cerevisiae yeast strains during the production of "Cachaça". Brazilian Journal of Microbiology, v. 36, n. 1, p.70-74, 2005.

DAVET, A.; CARVALHO, J. L. S.; DADALT, R. C.; VITUOSO, S., DIAS, J. F.; MIGUEL, M. D.; MIGUEL, O. G. Cereus jamacaru: a non buffered LC quantification method to nitrogen compounds. Chromatographia, v. 69, v. 2, p. 245-247, 2009.

DETTKE, G.A.; MILANEZE-GUTIERRE, M.A. Anatomia caulinar de espécies epífitas de Cactaceae, subfamília Cactoideae. Hoehnea, v. 35, n. 1, p. 583-595, 2008.

GUEDES, R. S.; ALVES, E. U.; GONÇALVES, E. P.; BRUNO, R. D. L.A.; BRAGA-JÚNIOR, J. M.; MEDEIROS, M. S. D. Germinação de sementes de Cereus jamacaru D.C. em diferentes substratos e temperaturas. Acta Scientiarum. Biological Sciences v. 31, n. 2, 159-164, 2009.

HERNÁNDEZ-GONZÁLEZ，O; VILLARREAL，O. B. Crassulacean acid metabolism photosynthesis in columnar cactus seedlings during ontogeny: the effect of light on nocturnal acidity accumulation and chlorophyll fluorescence. American Journal of Botany, v. 94, n. 8, p. 1344-1351, 2007.

JAYME, M. D. O.; CALEFFI, E. R.; JACOMINI, D.; LOPES, S. M. S.; GONÇALVES, R. A. C.; OLIVEIRA, A. J. B. Análise qualitativa dos polissacarídeos obtidos da cultura de calos de Cereus peruvianus Mill. (Cactaceae). BBR-Biochemistry and Biotechnology Reports, v. 2, n. 3, p. 138-141, 2013.

LANDGRAF, P. R. C.; PAIVA, P. D. O. Produção de mudas para jardim no estado de Minas Gerais. Ciência e Agrotecnologia, v. 33, n. 1, p. 127-131, 2009.

LORENZI, H. E.; MATOS, F. J. A. Plantas medicinais no Brasil: nativas e exóticas. Nova Odessa, SP: Instituto Plantarum, 2002.

LUCENA, C. M. D.; COSTA, G. M. D.; SOUSA, R. F. D.; CARVALHO, T. K. N.; MARREIROS, N. D. A.; ALVES, C. A. B.; LUCENA, R. F. P. Conhecimento local sobre cactáceas em comunidades rurais na mesorregião do sertão da Paraíba (Nordeste, Brasil). Biotemas, v. 25, n. 3, p. 281291, 2012.

MEIADO, M. V. Germinação de sementes de cactos do Brasil: fotoblastismo e temperaturas cardeais. Informativo ABRATES, v. 22, p. 10-15, 2012.
MEIADO, M. V.; ALBUQUERQUE, L. S. C.; ROCHA, E. A.; ROJAS-ARÉCHIGA M.; LEAL, I. R. Seed germination responses of Cereus jamacaru D.C. ssp. jamacaru (Cactaceae) to environmental factors. Plant Species Biology, v. 25, n. 2, p. 120-128, 2010. [AUTORES: cf. ano de publicação]

MESSIAS, J. B.; CARACIOLO, M. C.; OLIVEIRA, I. M. D.; MONTARROYOS, U. R.; BASTOS, I. V. G. A.; GUERRA, M. D. O.; SOUZA, I. Avaliação dos parâmetros hematológicos e bioquímicos de ratas no segundo terço da gestação submetidas à ação de extrato metanólico de Cereus jamacaru D.C., Cactaceae. Revista Brasileira de Farmacognosia, v. 20, p. 478-483, 2010.

OLIVEIRA, A. J. B.; MACHADO, M. F. P. S. Alkaloid production by callous tissue cultures of Cereus peruvianus (Cactaceae). Applied Biochemical and Biotechnology, v. 104, n. 2, p. 149-155, 2003.

OLIVEIRA, E. Elegia para uma Re(li)gião - Sudene, Nordeste, planejamento e conflitos de classes. 5. ed. Rio de Janeiro: Paz e Terra, 1987.

ORTEGA-BAES, P.; GODÍNEZ-ÁLVAREZ, H. Global diversity and conservation priorities in the Cactaceae. Biodiversity \& Conservation, v. 15, n. 3, p. 817-827, 2006.

PAULINO, R. C.; HENRIQUES, G. P. D. S. A.; COELHO, M. D. F. B.; NASCIMENTO-ARAÚJO, P. V. Riqueza e importância das plantas medicinais do Rio Grande do Norte. Revista de Biologia e Ciências da Terra, v. 11, p. 157-168, 2011.

PILETTI, R. Extração da mucilagem da tuna (Cereus hildmaniannus K. Schum) para aproveitamento industrial. 2011. 96p. Dissertação (Mestrado em Engenharia Química) - Universidade Federal de Santa Catarina, Florianópolis, 2011.

RAMALHO, C. I.; ANDRADE, A. P.; FÉLIX, L.P; LACERDA, A. V.; MARACAJÁ PB (2009) Flora arbóreoarbustiva em áreas de caatinga no semiárido baiano, Brasil. Revista Caatinga, v. 22, n. 2, p. 17-22, 2009.

REGO, M. M. In vitro seed germination of mandacaru (Cereus jamacaru DC.). Revista Caatinga, v. 22, n. 4, p. 34-38, 2009.

ROCHA, E. A.; AGRA, M. F. Flora of the Pico do Jabre, Paraíba, Brazil: Cactaceae Juss. Acta Botanica Brasilica, v. 16, n. 1, p.15-21, 2002.

SANTOS, G. M.; CRUZ, J. D. D.; BICHARA-FILHO, C. C., MARQUES, O. M.; AGUIAR, C. M. (2007). The use of cactus fruit food resources by social wasp (Hymenoptera, Vespidae, Polistinae) in an area of Caatinga (lpirá, Bahia, Brazil). Revista Brasileira de Zoologia, v. 24, p. 10521056, 2007. 
TAYLOR, N.; ZAPPI, D. Cacti of eastern Brazil. Kew: Royal Botanic Gardens, 2004.

VATTA, A. F.; KANDU-LELO, C.; ADEMOLA, I. O.; ELOFF, J. N. Direct anthelmintic effects of Cereus jamacaru (Cactaceae) on trichostrongylid nematodes of sheep in vivo studies. Veterinary Parasitology, v. 180, n. 3, p. 279-286, 2011.

VILLASEÑOR, M. A. A. Efecto del método de extración en las características químicas y físicas del mucílago del nopal (Opuntia fícus indica) y estúdio de su aplicación como recubrimiento comestible. 2008. 244f. Tese (Doutorado em Engenharia de Alimentos) - Universidade Politécnica de Valência, Valência, 2008.

WALLACE, R. S. Molecular systematic study of the Cactaceae: using chloroplast DNA variation to elucidate cactus phylogeny. Bradleya, v. 13, p. 1-12, 1995. 